\title{
A Probiotic, Lactobacillus fermentum ME-3, Has Antioxidative Capacity in Soft Cheese Spreads with Different Fats
}

\author{
S. Järvenpää, ${ }^{\star}$ R. L. Tahvonen, ${ }^{* 1,2}$ A. C. Ouwehand,† M. Sandell, ${ }^{\star}$ E. Järvenpää, ${ }^{\star}$ and S. Salminen† \\ *Department of Biochemistry and Food Chemistry, and \\ †Degree Programme in Health Biosciences and Functional Foods Forum, University of Turku, FIN-20014 Turku, Finland
}

\begin{abstract}
Our aim was to develop a prototype of a functional spread cheese containing both a specific probiotic and n-3 fatty acids and to analyze the viability of the probiotic and stability of n-3 fatty acids during 4 wk of shelf life. Lactobacillus fermentum ME-3 (Lf ME-3) isolated from a healthy Estonian child has been shown to have probiotic and antioxidative properties in several recent studies. In the current study this promising bacterial strain was combined with vegetable oils rich in nutritionally important $\alpha$-linolenic acid and with unflavored cheese to obtain soft cheese spreads with different fat contents. Lactobacillus fermentum ME-3 survived well in all cheeses although the viable count did not increase during 4 wk of storage. The fatty acid composition of cheese triacylglycerols remained stable, whereas the profile of volatile compounds changed: hexanal and pentanal disappeared and the proportion of some alcohols increased. The changes in the profile of volatile compounds show the reductive power of Lf ME-3. A functional spread cheese containing n-3 fatty acids can be prepared with the probiotic Lactobacillus fermentum ME-3 strain leading to a reduced need for chemical antioxidants.
\end{abstract}

Key words: Lactobacillus fermentum ME-3, fatty acid, soft cheese, volatile compound

\section{INTRODUCTION}

Probiotics are defined as live microbial food and feed ingredients beneficial to health (Salminen et al., 1998). Microorganisms representing many different species and genera have been used as probiotics. Most studies have mainly been focused on lactobacilli and bifidobacteria because of their long history of safe use in foods. One of these strains is Lactobacillus fermentum

Received December 4, 2006.

Accepted February 22, 2007.

${ }^{1}$ Corresponding author: raija.tahvonen@utu.fi

${ }^{2}$ Present address: FoodWest Ltd., Vaasantie 1C, FIN-60100 Seinäjoki, Finland.
ME-3 (Lf ME-3) that was isolated from the intestinal microbiota of a healthy, 1-yr-old Estonian child in 1995 (Sepp et al., 1997). This obligate heterofermentative lactic acid bacterium has been shown to exhibit significant antimicrobial and antioxidative properties in vitro (Kullisaar et al., 2002). It also has a history of safe use in foods in Estonia and other studies support its safety: Lf ME-3 does not contain hemolysins nor does it suppress the growth of common intestinal lactic acid bacteria (Mikelsaar et al., 2002; Songisepp et al., 2005). In laboratory animals Lf ME-3 has been demonstrated to benefit the general health status, to prevent the carrier state of Salmonella, and to improve mucosal antioxidative parameters (Mikelsaar et al., 2004; Truusalu et al., 2004). The results of volunteer trials are also promising, as the participants have tolerated well an experimental goat-milk yogurt containing Lf ME-3 without any adverse effects. Moreover, the Lf ME-3 fermented goat's milk expressed antiatherogenic potential; consumption of the yogurt prolonged resistance of the lipoprotein fraction to oxidation, lowered levels of peroxidized lipoproteins and 8-isoprostanes, decreased the glutathione redox ratio, and enhanced the total antioxidative activity (Kullisaar et al., 2003).

$\alpha$-Linolenic acid (ALA, 18:3n-3) is essential for mammals; hence, ALA must be obtained in the diet. It is clear that ALA has actions of its own (Fu and Sinclair, 2000 ) and acts as a substrate for $\beta$-oxidation and carbon recycling (Cunnane et al., 1999). Furthermore, it is cardioprotective (Djoussé et al., 2005, Gebauer et al., 2006). $\alpha$-Linolenic acid seems to modulate inflammation, which may be one of its benefits regarding cardiovascular disease (Harris, 2005; Basu et al., 2006). As with any polyunsaturated fatty acid (PUFA), it is very sensitive to lipid peroxidation (Halliwell and Gutteridge, 1999).

Oxidation of fatty acids in dairy products may have detrimental effects on flavor and storage stability. Usually, antioxidative substances are added to foods containing considerable amounts of different fatty acids. In a recent study, Lf ME-3 cells incorporated into a semisoft cheese expressed good total antioxidative activity (Songisepp et al., 2004). However, it has not been 
Table 1. Experimental design showing content of $\alpha$-linolenic acid (ALA) in different soft cheeses

\begin{tabular}{llll}
\hline Vegetable oil & \multicolumn{3}{c}{ ALA, g/g of cheese } \\
\hline Canola oil & $0 / 100^{1}$ & & \\
Canola oil & $0.5 / 100$ & & \\
Canola oil & $2.0 / 100$ & & \\
Flaxseed oil & $0 / 100^{1}$ & $0 / 60^{1}$ & $0 / 30^{1}$ \\
Flaxseed oil & $0.5 / 100$ & $0.5 / 60=0.8 / 100$ & $0.5 / 30=1.7 / 100$ \\
Flaxseed oil & $2.0 / 100$ & $2.0 / 60=3.3 / 100$ & $2.0 / 30=6.7 / 100$ \\
Camelina oil & $0 / 100^{1}$ & $0 / 60^{1}$ & $0 / 30^{1}$ \\
Camelina oil & $0.5 / 100$ & $0.5 / 60=0.8 / 100$ & $0.5 / 30=1.7 / 100$ \\
Camelina oil & $2.0 / 100$ & $2.0 / 60=3.3 / 100$ & $2.0 / 30=6.7 / 100$ \\
\hline
\end{tabular}

${ }^{1}$ These products were essentially identical. However, these oil-free blanks were evaluated to determine potential differences between products made on different days and from different curd batches.

assessed whether the antioxidative probiotic strain could prevent PUFA peroxidation and influence the composition of volatile compounds in soft cheeses enriched with different vegetable oils rich in ALA.

The aim of this study was to develop different cow's milk-based soft cheeses containing Lf ME-3 combined with vegetable oils (canola, flaxseed, and camelina) and to assess the survival of Lf ME-3, the changes in composition of fatty acids, and the changes in the profile of volatile compounds in the cheese products during $4 \mathrm{wk}$ of storage.

\section{MATERIALS AND METHODS}

\section{Cultures and Cheeses}

Lactobacillus fermentum ME-3 (DSM 14241) was supplied by University of Tartu (Tartu, Estonia). A laboratory-scale soft cheese was prepared by dripping whey from a commercial cow's milk-based curd (Vähälaktoosinen maitorahka; Maitokolmio, Toholampi, Finland). The commercial curd was produced by fermenting low-fat, low-lactose milk with a specific starter culture. It contained $0.2 \%$ fat, $<1 \%$ lactose, and potassium sorbate as preservative. Whey dripping was performed in 500-g batches in glass funnels lined with filter paper sachets. Dripping time and temperature was $2.5 \mathrm{~h}$ and $5^{\circ} \mathrm{C}$, and the curd was covered with aluminum foil to prevent dust contamination. Three or 4 batches were combined and homogenized to yield a base cheese. Next, $1 \mathrm{~mL}$ of Lf ME-3 $\left(\approx 7 \times 10^{9} \mathrm{cfu} / \mathrm{mL}\right)$ in PBS ( $\mathrm{pH}$ 7.2) and one of the vegetable oils were mixed with the base cheese to obtain $400 \mathrm{~g}$ of each product with ALA contents varying from 0 to $6.7 \mathrm{~g} / 100 \mathrm{~g}$ (Table 1). The 3 oils used in the study were canola oil (Can; Virgino rypsiöljy; Kankaisten öljykasvit Oy, Hämeenlinna, Finland), flaxseed oil (Fla; Pellavainen pellavansiemenöljy; Elixi Oil Oy, Somero, Finland), and camelina oil (Cam; Camelina öljy; Camelina Oy, Raisio, Finland); all oils were cold pressed.
Treatment designations are shown in Table 1; the numbers following the oil designation (Can, Cam, and Fla) indicate the ALA content in each cheese ( $g$ of ALA/ $\mathrm{g}$ of cheese). The mixing was done first with an ethanolcleaned spatula and then carefully with a hand mixer (Bamix Mono; ESGE AG, Mettlen, Switzerland) in the same food-grade polypropylene containers in which the cheeses would be stored for the next 4 wk at $5^{\circ} \mathrm{C}$. One replicate of each cheese variant was prepared. In addition, different blank cheeses were prepared: oil-free blanks (base cheese and Lf ME-3) and probiotic-free blanks (base cheese mixed with vegetable oil).

\section{Microbiological Analysis}

Bacterial analysis of cheeses was performed on the day of production (d 0 ) and on d 4, 7, 14, 21, and 28. Samples of $1 \mathrm{~g}$ were serially diluted $\left(10^{-4}\right.$ to $\left.10^{-6}\right)$ in PBS ( $\mathrm{pH}$ 7.2), and dilutions were plated on de Man, Rogosa, and Sharpe (MRS; Oxoid Ltd., Basingstoke, UK) agar (European bacteriological agar, Laboratorios Conda, Madrid, Spain). The plates were incubated in an anaerobic atmosphere $\left(10 \% \mathrm{H}_{2}, 10 \% \mathrm{CO}_{2}, 80 \% \mathrm{~N}_{2}\right)$ at $37^{\circ} \mathrm{C}$ overnight. The counts (cfu/g) of Lf ME-3 were estimated by counting of all visible colonies (white colonies with regular edges). This estimation method was feasible because the diluted samples $\left(10^{-1}\right.$ to $\left.10^{-4}\right)$ of the curd without Lf ME-3 addition did not form colonies during the incubation period on MRS. Each time when the growth of bacteria was tested, additional cheese samples were put in glass vials and stored at $-86^{\circ} \mathrm{C}$ until subsequent analyses.

\section{Extraction of Lipids}

The method used in the extraction of lipids was a modification of the Folch procedure (Folch et al., 1957). The extracted samples were from products containing added vegetable oil. Samples were thawed at $4^{\circ} \mathrm{C}$ before weighing. An amount of cheese corresponding to at least $50 \mathrm{mg}$ of lipids was mixed, as a whole or in several lots, with 18 volumes of $2: 1$ (vol/vol) chloroform:methanol in stoppered glass tubes. The mixture was vortexed for 2 min. Then, 6 volumes of $0.7 \%$ (wt/vol) sodium chloride (aqueous) solution were added and the tubes were inverted 20 times. The mixtures were separated into 2 phases using a DuPont Sorvall TC centrifuge (Sorvall Instruments, Newton, CT) equipped with an H-400 rotor $(4 \mathrm{~min}, 950 \times \mathrm{g})$. The lower phase was transferred with a Pasteur pipette to a weighed test tube. The solvents were evaporated under a flow of nitrogen and the tube was weighed again to determine the approximate mass of lipids. The solids were dissolved in hexane containing $0.02 \%$ butylated hydroxytoluene (BHT, as an 
antioxidant retarding lipid oxidation) to obtain a lipid solution of about $50 \mathrm{mg} / \mathrm{mL}$, which was transferred into autosampler vials. The headspace volume of the vials was replaced with nitrogen, and finally the vials were capped and stored at $-70^{\circ} \mathrm{C}$. Two subsamples of each cheese sample of different days of analysis were extracted.

\section{Preparation of Fatty Acid Methyl Esters}

Fatty acid methyl esters were prepared by a modification of the base-catalyzed transesterification method of Christie (1982). Three hundred microliters of the lipid solution was flushed with nitrogen until the solvent had evaporated. Eight hundred microliters of dry diethyl ether and $25 \mu \mathrm{L}$ of methyl acetate were added. After mixing, $25 \mu \mathrm{L}$ of $1.0 \mathrm{M}$ sodium methoxide was added to start the transesterification process and the liquids were vortexed for $30 \mathrm{~s}$. The reaction was stopped with $6 \mu \mathrm{L}$ of concentrated acetic acid after $5 \mathrm{~min}$. The solution was centrifuged using an Heraeus Sepatech Labofuge 200 (Heraeus Instruments, Osterode, Germany; 5 min, $1,915 \times g$ ) and the clear supernatant was transferred into an autosampler vial and dried with a gentle nitrogen flow. The esters were dissolved in 800 $\mu \mathrm{L}$ of hexane containing $0.02 \%$ BHT.

\section{GC Analysis of Fatty Acid Methyl Esters}

Fatty acid profiles of the samples were determined using gas chromatography. The esters were analyzed using a Shimadzu GC-17A gas chromatograph (Kyoto, Japan) equipped with a flame-ionization detector, Shimadzu AOC-17 auto injector, and fused-silica capillary column (Supelcowax-10, $30 \mathrm{~m} \times 0.32 \mathrm{~mm}$ i.d., film thickness of $0.25 \mu \mathrm{m}$; Supelco, Inc., Bellefonte, PA). The system was controlled with Shimadzu CLASS-VP Version 4.0 software. The temperature program was $2 \mathrm{~min}$ at $120^{\circ} \mathrm{C}$, increased at $4^{\circ} \mathrm{C} / \mathrm{min}$ to $200^{\circ} \mathrm{C}, 55 \mathrm{~min}$ at $200^{\circ} \mathrm{C}$, increased at $10^{\circ} \mathrm{C} / \mathrm{min}$ to $240^{\circ} \mathrm{C}$, and $10 \mathrm{~min}$ at $240^{\circ} \mathrm{C}$. The temperatures of the injector and detector were 225 and $240^{\circ} \mathrm{C}$, respectively. Helium was used as a carrier gas with a flow rate of $1.5 \mathrm{~mL} / \mathrm{min}$ and a split ratio of about $15: 1$; the injection volume was $0.5 \mu \mathrm{L}$. Fatty acids with at least 14 acyl carbons were identified using a commercial mixture of fatty acid methyl esters (mixture 68 D; Nu-Chek Prep, Inc., Elysian, MN).

\section{Solid-Phase Microextraction-GC-MS Analysis of Volatiles}

The cheese samples weighing $1.0 \mathrm{~g}$ were taken from glass vials kept at $-20^{\circ} \mathrm{C}$ for about 1 to $3 \mathrm{mo}$ (5 to $6 \mathrm{mo}$ below $-70^{\circ} \mathrm{C}$ before this). The headspace was equili- brated in capped dark glass bottles $(40 \mathrm{~mL})$ for $20 \mathrm{~min}$ at room temperature $\left(21^{\circ} \mathrm{C}\right)$. Next, the sample volatiles were extracted for 30 min by using a solid-phase microextraction (SPME) device (Supelco, Bellefonte, PA) using a StableFlex DVB/CAR/PDMS fiber (Supelco, Inc.). The volatiles were desorbed by keeping the fiber for $6 \mathrm{~min}$ in the injector of a Shimadzu GC-17A gas chromatograph connected to a Shimadzu QP5000 mass spectrometer. The column used was DB-1701 (30 m $\times$ $0.25 \mathrm{~mm}$ i.d., film thickness $0.25 \mu \mathrm{m}$; J\&W Scientific, Agilent Technologies, Folsom, CA), and the temperature program was as follows: $6 \mathrm{~min}$ at $35^{\circ} \mathrm{C}$, increased at $7^{\circ} \mathrm{C} / \mathrm{min}$ to $80^{\circ} \mathrm{C}$, increased at $5^{\circ} \mathrm{C} / \mathrm{min}$ to $130^{\circ} \mathrm{C}$, increased at $7^{\circ} \mathrm{C} / \mathrm{min}$ to $180^{\circ} \mathrm{C}$, and finally increased at $10^{\circ} \mathrm{C} / \mathrm{min}$ to $230^{\circ} \mathrm{C}$, where the temperature was held for $4 \mathrm{~min}$. The split valve opened $5 \mathrm{~min}$ after the start. The temperatures of the injector and interface were both $230^{\circ} \mathrm{C}$. The ionization energy was $70 \mathrm{eV}$, the detection voltage was $1.20 \mathrm{kV}$, and the compounds were monitored over the range $\mathrm{m} / z 40$ to 350 . The GC-MS system was controlled with Shimadzu Class-5000 Version 1.2 software and the volatiles were tentatively identified using the Shimadzu Wiley 229 mass spectral library. Only samples from $d 0$ and 28 of the products with the greatest fat contents (Can 2.0/100, Fla 2.0/30, Cam 2.0/ 30 ) and the 3 oil-free blanks (i.e., base cheese with Lf ME-3) were analyzed. The day-to-day performance of the GC-MS system was followed with a Can 2.0/100 probiotic-free blank, which was otherwise identical to the product Can 2.0/100 except that it did not contain Lf ME-3.

\section{Statistical Methods}

Culture experiments were performed once per time point, and all other assays were conducted in duplicate. For the fatty acid assays, statistically significant differences $(P<0.05)$ were calculated with a 2 -tailed pairedsamples $t$-test. Statistical analysis was performed using SPSS software (version 10.1., SPSS Inc., Chiacgo, IL).

\section{RESULTS}

\section{Viable Counts}

The viable counts of Lf ME-3 remained stable throughout the 4-wk storage period. Results were similar for all products, ranging from 3.4 to $8.0 \times 10^{7} \mathrm{cfu} / \mathrm{g}$ on d 0 to 2.0 to $4.8 \times 10^{7} \mathrm{cfu} / \mathrm{g}$ on d 28 (results not shown).

\section{Fatty Acid Profile}

Differences in the proportions of analyzed fatty acids between stored $(28 \mathrm{~d})$ and fresh products were not statistically significant $(P \geq 0.753$ in Can, $P \geq 0.751$ in Fla, 
Table 2. Proportion of $\alpha$-linolenic acid (ALA) in different soft cheeses during $28 \mathrm{~d}$ of storage

\begin{tabular}{lccc}
\hline & \multicolumn{3}{c}{$\mathrm{ALA}^{2} \%$} \\
\cline { 2 - 4 } Cheese $^{1}$ & $\mathrm{~d} \mathrm{0}$ & $\mathrm{d} 14$ & $\mathrm{~d} 28$ \\
\hline Can 0.5/100 & 11.2 & 11.1 & 11.2 \\
Can 2.0/100 & 11.7 & 11.5 & 11.5 \\
Fla 0.5/100 & 44.4 & 44.3 & 44.2 \\
Fla 2.0/100 & 54.7 & 54.7 & 54.7 \\
Fla 0.5/60 & 49.5 & 49.5 & 49.6 \\
Fla 2.0/60 & 56.4 & 55.9 & 56.5 \\
Fla 0.5/30 & 54.0 & 54.1 & 54.1 \\
Fla 2.0/30 & 57.8 & 57.9 & 57.8 \\
Cam 0.5/100 & 34.4 & 34.4 & 34.4 \\
Cam 2.0/100 & 39.9 & 39.8 & 39.8 \\
Cam 0.5/60 & 37.2 & 37.4 & 37.4 \\
Cam 2.0/60 & 40.9 & 40.9 & 40.8 \\
Cam 0.5/30 & 39.6 & 39.5 & 39.5 \\
Cam 2.0/30 & 41.5 & 41.3 & 41.5 \\
\hline
\end{tabular}

${ }^{1}$ Cheeses were mixed with canola (Can), flaxseed (Fla), or camelina (Cam) oils, with the ALA content given in grams of ALA/grams of product (e.g., Can $0.5 / 100=$ cheese spread made with canola oil and $0.5 \mathrm{~g}$ of ALA per $100 \mathrm{~g}$ of product).

${ }^{2}$ Proportion of ALA methyl ester (area \% of total identified cheese fatty acid methyl esters).

and $P \geq 0.764$ in Cam products). Proportions of the nutritionally important ALA on d 0, 14, and 28 are shown as an example (Table 2).

\section{Volatile Compounds}

Common volatile compounds of cheeses were identified in the SPME-GC-MS chromatograms. An exception was 2-methyl-2-propanol, which has never been associated with dairy or fat-derived volatiles. Octane, pentanal, 1-pentanol, and unknowns 1, 3, 4, and 5 were found in Can 2.0/100, whereas limonene, 2-methyl-1-butanol, and 3-methyl-1-butanol were found in Cam 2.0/30. Unknown 3 was present also in Can 0/100 and in Fla 0/30.

The major changes in the proportions of volatiles occurred in the same compounds both in oil-containing (Table 3) and oil-free (Figure 1) products although the extent of the change differed. The proportions of acetic acid, ethanol, and 2-methyl-2-propanol increased, whereas acetoin disappeared completely during storage. Table 4 shows that LA seems to be the main precursor of hexanal and ALA does not affect hexanal production. During storage, however, hexanal disappeared, whereas the proportion of 1-hexanol increased. As can be seen in Figure 2, both the oil and the probiotic induced changes in composition of cheeses during storage.

\section{DISCUSSION}

We have assessed the stability and viability of Lactobacillus fermentum ME-3 in soft cheese manufactured with different vegetable oils during 4 wk of storage.
Stable viable counts were accompanied by a reduction of volatile aldehyde compounds. The proportion of ALA did not change.

Viable counts of Lf ME-3 in all cheeses remained stable throughout the storage period. Also, several shifts in the profiles of volatile compounds (Table 3) indicated that the metabolic activity of Lf ME-3 was sustained. This ability of Lf ME-3 to tolerate low temperatures supports earlier findings of Songisepp et al. (2004). However, the curd used as raw material for the cheeses contained a preservative, potassium sorbate, which may have somewhat suppressed the growth of Lf ME-3. Furthermore, no emulsifiers were used despite the fact that some cheeses would have required them for commercial use. Emulsifiers were excluded because of the possibility that they might affect the survival of Lf ME-3 and act as antioxidants.

In a recent study (Kankaanpää et al., 2001), free PUFA at concentrations of 10 to $40 \mu \mathrm{g} / \mathrm{mL}$ in growth medium inhibited the multiplication and mucus adhesion of tested probiotic bacterial strains, but the viability of bacteria was not impaired. Growth inhibition may, however, compromise the action of indigenous microflora or supplemented probiotics. In the same study, bacterial adhesion sites on Caco-2 cells were altered by PUFA. In a later study, PUFA added to growth medium resulted in the incorporation of the PUFA into bacterial lipids of tested lactobacilli (Kankaanpää et al., 2004). Moreover, free PUFA induced changes in the proportions of bacterial fatty acids but these changes resulted only in minor changes in the hydrophilic or hydrophobic characteristics of lactobacilli (tested with organic solvents). The minor changes in hydrophobicity are unlikely to explain the observed effects of free PUFA on bacterial adhesion to mucus and epithelial cells (Kankaanpää et al., 2001), but do indicate that altered fatty acid compositions of probiotics may predominantly influence other factors associated with the microbial adhesion process, probably by influencing bacterial membrane fluidity and membrane-lipopeptide interactions.

It is possible that the minor levels of free fatty acids or perhaps the esterified oil fatty acids in the tested cheeses prevented the growth of Lf ME-3 to some extent, but as the viable counts remained stable in both oil cheeses and blanks (practically fat-free), the effect was, at most, very slight. The question concerning modified adhesion to intestinal surfaces remains open.

The fatty acid composition of cheese triacylglycerols did not change during 4 wk of storage, suggesting that extensive fatty acid oxidation did not occur. However, if there were lipolysis-derived free fatty acids, they may have oxidized. On the other hand, there are no clear signs of significant lipid oxidation in volatile chromato- 
Table 3. Relative proportion (\% of considered total area) of volatiles in 3 different high-fat soft cheeses at d 0 and 28 (means of 2 measurements)

\begin{tabular}{|c|c|c|c|c|c|c|}
\hline \multirow[b]{3}{*}{ Volatile } & \multicolumn{6}{|c|}{ Cheeses $^{1}$} \\
\hline & \multicolumn{2}{|c|}{ Can 2.0/100 } & \multicolumn{2}{|c|}{ Fla 2.0/30 } & \multicolumn{2}{|c|}{ Cam 2.0/30 } \\
\hline & d 0 & $\mathrm{~d} 28$ & d 0 & d 28 & d 0 & d 28 \\
\hline Unknown 1 & 1.1 & 1.5 & $-^{2}$ & - & - & - \\
\hline Ethanol & 14.3 & 43.7 & 47.4 & 68.0 & 47.8 & 64.6 \\
\hline 2-Propanone (acetone) & 6.6 & 10.1 & 1.8 & 2.1 & 1.3 & 1.7 \\
\hline Unknown 2 & 1.6 & 2.2 & 1.0 & 2.3 & 1.5 & 2.1 \\
\hline 2-Methyl-2-propanol & - & 6.0 & 5.2 & 8.4 & 9.4 & 13.4 \\
\hline Unknown 3 & 1.7 & 1.0 & - & - & - & - \\
\hline Unknown 4 & - & 0.6 & - & - & - & - \\
\hline Pentanal & 0.6 & - & - & - & - & - \\
\hline Ethanoic acid (acetic acid) & 6.3 & 16.1 & 7.0 & 10.9 & 4.7 & 7.5 \\
\hline Octane & 1.9 & 4.5 & - & - & - & - \\
\hline 3-Methyl-1-butanol & - & - & - & - & - & 1.5 \\
\hline 2-Methyl-1-butanol & - & - & - & - & - & 1.7 \\
\hline 3-Hydroxy-2-butanone (acetoin) & 51.0 & - & 24.5 & - & 28.1 & - \\
\hline 1-Pentanol & - & 2.6 & - & - & - & - \\
\hline Hexanal & 12.5 & - & 5.5 & - & 2.9 & - \\
\hline Unknown 5 & 1.0 & 1.5 & - & - & - & - \\
\hline 1-Hexanol & 1.4 & 10.2 & 2.2 & 4.4 & - & 1.8 \\
\hline 4-Isopropenyl-1-methyl-cyclohexene (limonene) & - & - & - & - & 2.7 & 3.5 \\
\hline Unknown 6 & - & - & 5.4 & 4.0 & 1.6 & 2.1 \\
\hline
\end{tabular}

${ }^{1}$ The names consist of an abbreviation of the oil the products contain $(\mathrm{Can}=$ canola oil, Fla = flaxseed oil, Cam = camelina oil) and the content of $\alpha$-linolenic acid (g of $\alpha$-linolenic acid/g of product).

${ }^{2} \mathrm{~A}$ peak was not detected or was below the limits for positive identification.

grams. No aldehydes (important products of FA oxidation) were detected in stored high-fat samples.

Most of the volatiles found were those commonly detected with different analytical procedures (Chin et al., 1996; Alewijn et al., 2003; Beltran et al., 2005) in sev- eral hard (Bosset et al., 1997; Engels et al., 1997) and soft cheeses (Sable and Cottenceau, 1999; Sunesen et al., 2002).

The proportion of hexanal, an indicator of lipid oxidation (van Ruth et al., 2000; Shahidi and Wanasundara,

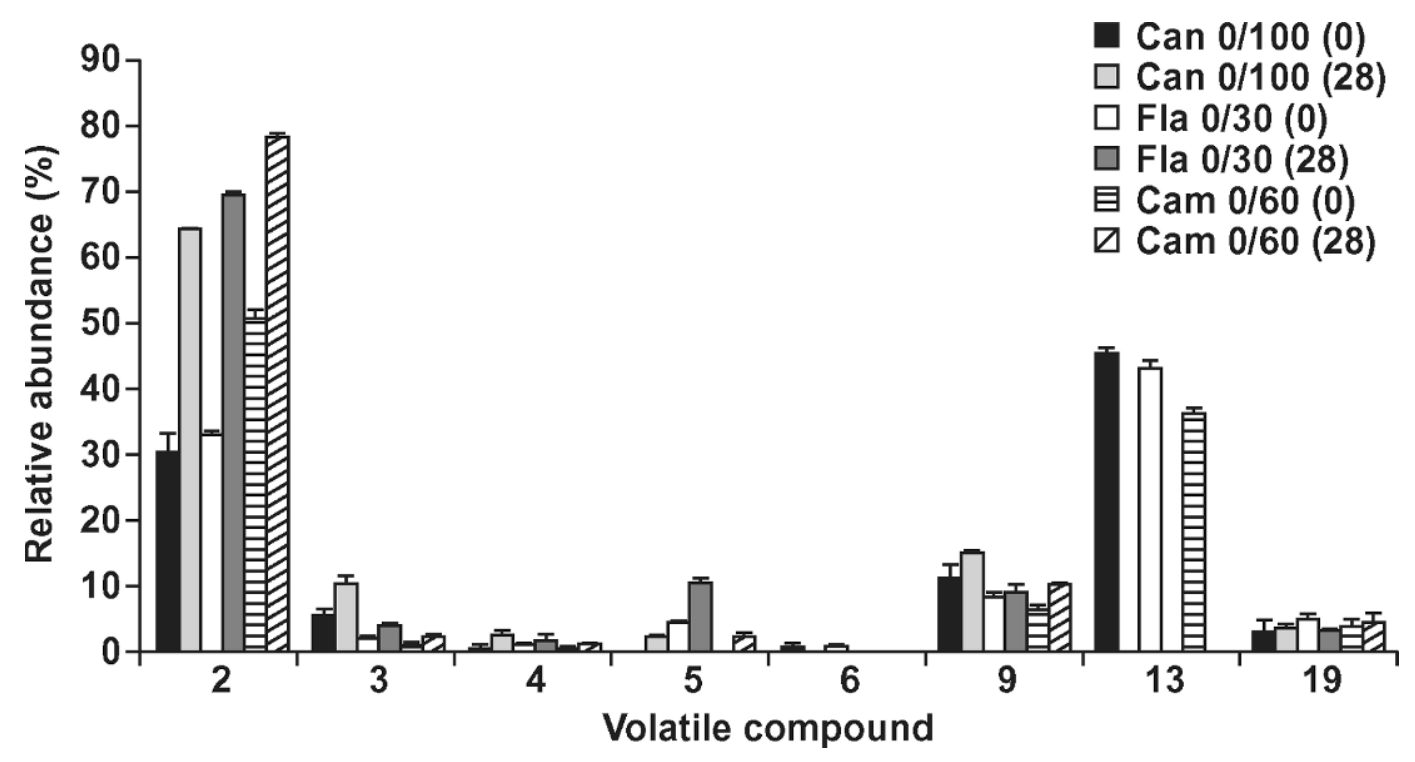

Figure 1. Relative abundances (\%) of volatile compounds in 3 oil-free (blank) cheeses. Can, Fla, and Cam refer to cheese spreads made with canola, flaxseed, and camelina oils, respectively; the numbers in parentheses after the product names indicate days (d) since cheese preparation. Volatile compounds: $2=$ ethanol; $3=2$-propanone (acetone); $4=$ unknown; $5=2$-methyl-2-propanol; $6=$ unknown; $9=$ ethanoic (acetic) acid; 13 = 3-hydroxy-2-butanone (acetoin); and $19=$ unknown. 
Table 4. Properties of high-fat soft cheeses (means of 2 samples)

\begin{tabular}{lccc}
\hline & \multicolumn{3}{c}{ Cheese $^{1}$} \\
\cline { 2 - 4 } Property & Can 2.0/100 & Fla 2.0/30 & Cam 2.0/30 \\
\hline Total vegetable fat, ${ }^{2} \%$ & 20.0 & 11.3 & 17.1 \\
Linoleic acid, $^{2} \%$ & 4.4 & 1.9 & 2.2 \\
$\alpha$-Linolenic acid, ${ }^{2} \%$ & 2.0 & 6.7 & 6.7 \\
Hexanal, $^{3} \%$ (d 0) & 12.5 & 5.5 & 2.9 \\
1-Hexanol, ${ }^{3} \%$ (d 28) & 10.2 & 4.4 & 1.8 \\
\hline
\end{tabular}

${ }^{1}$ The names consist of an abbreviation of the oil the products contain $(\mathrm{Can}=$ canola oil, $\mathrm{Fla}=$ flaxseed oil, $\mathrm{Cam}=$ camelina oil $)$ and the content of $\alpha$-linolenic acid (g of $\alpha$-linolenic acid/g of product).

${ }^{2}$ Proportion (wt/wt, \%).

${ }^{3}$ Proportion (\% of total volatile peak area).

2002), did not increase during storage. The short- and medium-chain FFA that are usually the most abundant volatile compounds of soft cheeses (Sable and Cottenceau, 1999) were not observed in the analyzed high-fat cheeses of this study. Acetic acid was an exception in this regard but because its proportion was approximately the same in oil-free blanks as in oil products, acetic acid must have formed mainly during normal microbial fermentation and not as a result of lipolysis or lipid oxidation.

The absence of both hexanal and 1-hexanol in fatfree blanks suggests that these compounds were oil derived and that the oils were oxidized to some extent before preparation of the cheeses. Hexanal, which is a characteristic oxidation product of linoleic acid (Fran- kel, 1982; Frankel et al., 1992), seemed to be converted into 1-hexanol and possibly into other products (Table 3). Canola oil has the highest concentration of linoleic acid among the oils used in this study, which at least partly accounted for the large proportions of hexanal before and 1-hexanol after storage of the Can 2.0/100 product (Table 4). In addition, pentanal disappeared and was apparently converted into 1-pentanol, suggesting the reductive power of Lf ME-3 rich in reduced glutathione.

Figure 2 demonstrates that the volatile composition of Can 2.0/100 blank (probiotic-free) on d 28 (mean of 7 replicates) was almost identical to product Can 2.0/ 100 on d 0; these 2 products differed considerably from Can 2.0/100 on $d$ 28. For comparison, the mean values of the 3 analyzed blanks on d 0 and 28 are also shown. To summarize, both the identity of the oils used and the added probiotic induced changes in the composition of cheeses during storage.

Lactobacillus fermentum ME-3 survived well through 4 wk of storage at $5^{\circ} \mathrm{C}$ in different soft cheeses with variable fat contents. Lipid peroxidation was not assessed because the fatty acid composition of cheese triacylglycerols remained stable and no aldehydes were found at the end of the storage period. Volatile profiles of different products varied during storage, indicating the reductive power of Lf ME-3.

In conclusion, it is feasible to make probiotic soft cheeses with good stability using the Lactobacillus fer-

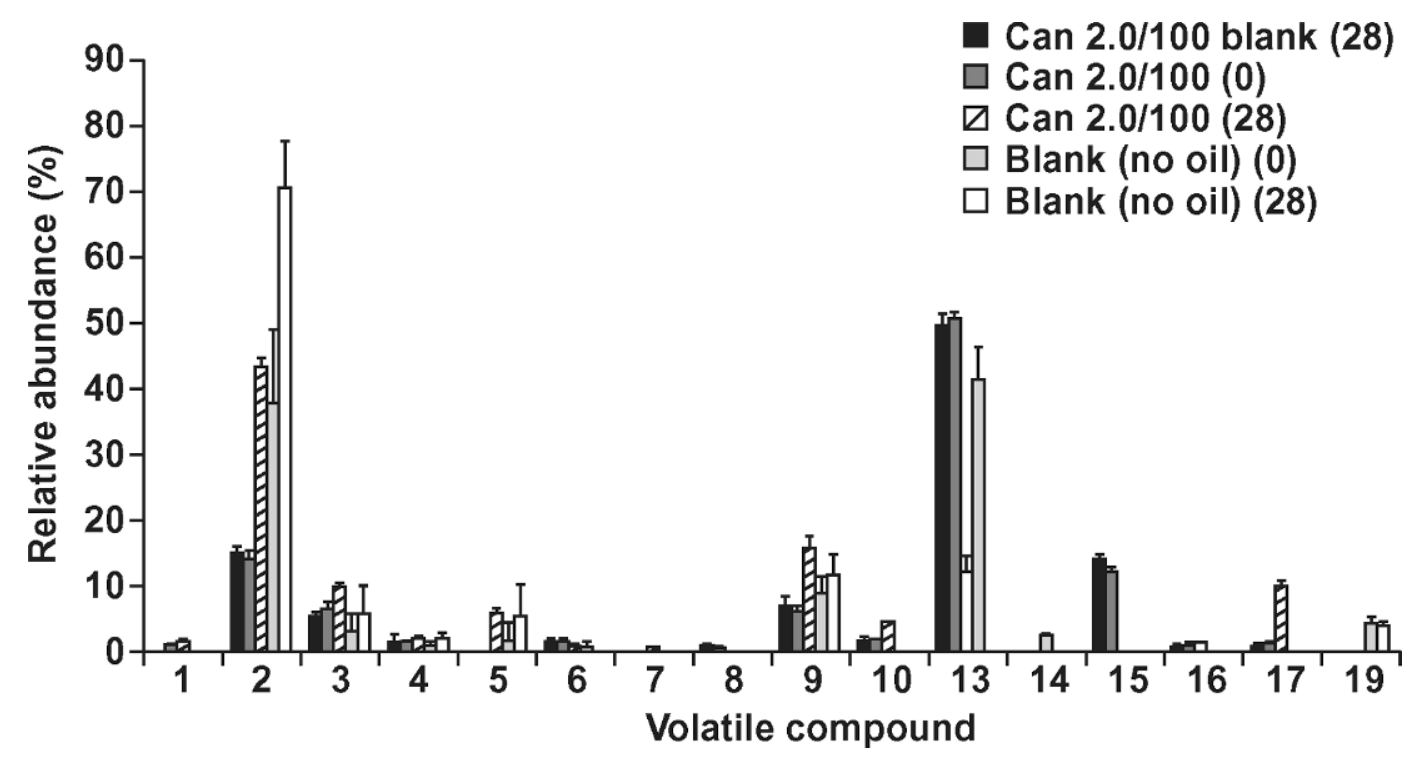

Figure 2. Relative abundances (\%) of volatile compounds in canola (Can) oil cheeses with (Can 2.0/100) and without (Can 2.0/100 blank) added Lactobacillus fermentum ME-3 and the average results of oil-free cheeses with added Lactobacillus fermentum ME-3 at 0 and $28 \mathrm{~d}$ after cheese preparation. Volatile compounds: 1 = unknown; 2 = ethanol; $3=2$-propanone (acetone); $4=$ unknown; $5=2$-methyl-2-propanol; 6 = unknown; 7 = unknown; 8 = pentanal; 9 = ethanoic (acetic) acid; $10=$ octane; $13=3$-hydroxy-2-butanone (acetoin); $14=1$-pentanol; 15 = hexanal; 16 = unknown; $17=1$-hexanol; and $19=$ unknown . 
mentum ME-3 strain. Moreover, the Lf ME-3 strain survived in each oil environment. Thus, the oil producing the best taste and the greatest amount of nutritionally important ALA could be selected for further product development.

\section{ACKNOWLEDGMENTS}

This study was supported by the dairy company Maitokolmio and the National Technology Agency of Finland (TEKES). We thank the University of Tartu for providing us with Lactobacillus fermentum ME-3, Petra Larmo and Kaisa Linderborg for technical assistance and for revision of the English language. Thanks to Epp Songisepp for technical help in producing the combined cheeses and Mihkel Zilmer and Marika Mikelsaar for their constructive advice in preparing the manuscript.

\section{REFERENCES}

Alewijn, M., E. L. Shwinski, and J. T. M. Wouters. 2003. A fast and simple method for quantitative determination of fat-derived medium and low-volatile compounds in cheese. Int. Dairy J. 13:733-741.

Basu, A., S. Devaraj, and I. Jialal. 2006. Dietary factors that promote or retard inflammation. Arterioscler. Thromb. Vasc. Biol. 26:995-1001.

Beltran, G., M. P. Aguilera, and M. H. Gordon. 2005. Solid-phase microextraction of volatile oxidation compounds in oil-in-water emulsions. Food Chem. 92:401-406.

Bosset, J.O., U. Butikofer, R. Gauch, and R. Sieber. 1997. Ripening of Emmental cheese wrapped in foil with and without addition of Lactobacillus casei subsp. casei. 2. Gas chromatographic investigation of some volatile neutral compounds using dynamic headspace analysis. Lebensm. Wiss. Technol. 30:464-470.

Chin, H. W., R. A. Bernhard, and M. Rosenberg. 1996. Solid phase microextraction for cheese volatile compound analysis. J. Food Sci. 61:1118-1122.

Christie, W. W. 1982. A simple procedure for rapid transmethylation of glycerolipids and cholesterylesters. J. Lipid Res. 23:1072-1075.

Cunnane, S. C., C. R. Menard, S. S. Likhodii, J. T. Brenna, and M. A. Crawford. 1999. Carbon recycling into de novo lipogenesis is a major pathway in neonatal metabolism of linoleate and $\alpha$ linolenate. Prostaglandins Leukot. Essent. Fatty Acids 60:387392.

Djoussé, L., D. K. Arnett, J. Carr, J. H. Eckfeldt, P. N. Hopkins, M. A. Province, and R. C. Ellison. 2005. Dietary linolenic acid is inversely associated with calcified atherosclerotic plaque in the coronary arteries. The National Heart, Lung, and Blood Institute family heart study. Circulation 111:2921-2926.

Engels, W. J. M., R. Dekker, C. de Jong, R. Neeter, and S. Visser. 1997. A comparative study of volatile compounds in the watersoluble fraction of various types of ripened cheese. Int. Dairy J. 7:255-263.

Folch, J., M. Lees, and G. H. Sloane Stanley. 1957. A simple method for the isolation and purification of total lipids from animal tissue. J. Biol. Chem. 226:497-509.

Frankel, E. N. 1982. Volatile lipid oxidation products. Prog. Lipid Res. 22:1-33.

Frankel, E. N., E. Selke, W. E. Neff, and K. Miyashita. 1992. Autoxidation of polyunsaturated triacylglycerols. IV. Volatile decomposi- tion products from triacylglycerols containing linoleate and linolenate. Lipids 27:442-446.

Fu, Z., and A. J. Sinclair. 2000. Novel pathway of metabolism of $\alpha$ linolenic acid in the guinea pig. Pediatr. Res. 47:414-417.

Gebauer, S. K., T. L. Psota, W. S. Harris, and P. M. Kris-Etherton. 2006. N-3 Fatty acid dietary recommendations and food sources to achieve essentiality and cardiovascular benefits. Am. J. Clin. Nutr. 83(Suppl.):1526S-1535S.

Halliwell, B., and J. M. C. Gutteridge. 1999. Free radicals in biology and medicine. Oxford University Press, New York, NY.

Harris, W. S. 2005. Extending the cardiovascular benefits of omega3 fatty acids. Curr. Atheroscler. Rep. 7:375-380.

Kankaanpää, P. E., S. J. Salminen, E. Isolauri, and Y. K. Lee. 2001. The influence of polyunsaturated fatty acids on probiotic growth and adhesion. FEMS Microbiol. Lett. 194:149-153.

Kankaanpää, P., B. Yang, H. Kallio, E. Isolauri, and S. Salminen. 2004. Effects of polyunsaturated fatty acids in growth medium on lipid composition and on physicochemical surface properties of lactobacilli. Appl. Environ. Microbiol. 70:129-136.

Kullisaar, T., E. Songisepp, M. Mikelsaar, K. Zilmer, T. Vihalemm, and M. Zilmer. 2003. Antioxidative probiotic fermented goats' milk decreases oxidative stress-mediated atherogenicity in human subjects. Br. J. Nutr. 90:449-456.

Kullisaar, T., M. Zilmer, M. Mikelsaar, T. Vihalemm, H. Annuk, C. Kairane, and A. Kilk. 2002. Two antioxidative lactobacilli strains as promising probiotics. Int. J. Food Microbiol. 72:215-224.

Mikelsaar, M., H. Annuk, J. Shchepetova, R. Mändar, E. Sepp, and B. Björksten. 2002. Intestinal lactobacilli of Estonian and Swedish children. Microb. Ecol. Health Dis. 14:75-80.

Mikelsaar, R., K. Truusalu, M. Murde, P. Naaber, and M. Mikelsaar. 2004. Probiotic lactobacilli enhance eradication of Salmonella typhimurium in animal model. Page 61 in Abstr. 44th Interscience Conf. Antimicrobial Agents and Chemotherapy. Am. Soc. Microbiol., Washington, DC.

Sable, S., and G. Cottenceau. 1999. Current knowledge of soft cheeses flavor and related compounds. J. Agric. Food Chem. 47:48254836.

Salminen, S., C. Bouley, M. C. Boutron-Ruault, J. H. Cummings, A. Franck, G. R. Gibson, E. Isolauri, M. C. Moreau, M. Roberfroid, and I. Rowland. 1998. Functional food science and gastrointestinal physiology and function. Br. J. Nutr. 80(Suppl. 1):S147-S171.

Sepp, E., K. Julge, M. Vasar, P. Naaber, B. Björksten, and M. Mikelsaar. 1997. Intestinal microflora of Estonian and Swedish infants. Acta Paediatr. 86:956-961.

Shahidi, F., and U. N. Wanasundara. 2002. Methods for measuring oxidative rancidity in fats and oils. Pages $474-475$ in Food Lipids: Chemistry, Nutrition and Biotechnology. Second ed., revised and expanded. C. C. Akoh and D. B. Min, ed. Marcel Dekker, New York, NY.

Songisepp, E., J. Kaals, T. Kullisaar, R. Mädar, P. Hütt, M. Zilmer, and M. Mikelsaar. 2005. Evaluation of the functional efficacy of an antioxidative probiotic in healthy volunteers. Nutr. J. 4:22.

Songisepp, E., T. Kullisaar, P. Hutt, P. Elias, T. Brilene, M. Zilmer, and M. Mikelsaar. 2004. A new probiotic cheese with antioxidative and antimicrobial activity. J. Dairy Sci. 87:2017-2023.

Sunesen, L. O., P. Lund, J. Sørensen, and G. Hølmer. 2002. Development of volatile compounds in processed cheese during storage. Lebensm. Wiss. Technol. 35:128-134.

Truusalu, K., P. Naaber, T. Kullisaar, H. Tamm, R. H. Mikelsaar, K. Zilmer, A. Rehema, M. Zilmer, and M. Mikelsaar. 2004. The influence of antibacterial and antioxidative probiotic lactobacilli on gut mucosa in a mouse model of Salmonella infection. Microb. Ecol. Health Dis. 16:180-187.

van Ruth, S. M., J. P. Roozen, and F. J. Jansen. 2000. Aroma profiles of vegetable oils varying in fatty acid composition vs. concentrations of primary and secondary lipid oxidation products. Nahrung 44:318-322. 